\title{
Pacientes oncológicos: um olhar sobre as dificuldades vivenciadas pelos familiares cuidadores.
}

\author{
Flávia Sordi Volpato* \\ Gilcinéia Rose S. dos Santos**
}

\section{Introdução}

Os pacientes oncológicos necessitam de uma ajuda contínua em sua vida diária. Geralmente um dos familiares se encarrega dessas atividades, dedicando-se por um longo período a esses cuidados. Como a doença crônica pode ou não perdurar anos a fio em uma evolução contínua, esses cuidadores geralmente acabam por abdicar de suas vidas em função dos pacientes.

Em muitos casos, ao receber o diagnóstico de câncer de um ente querido, toda a estrutura familiar sofre alterações, principalmente o membro que se dedicará aos cuidados do paciente, pois, de acordo com Santos; Sebastiani (2001), nem sempre a família e os familiares apresentam uma estrutura perfeita para absorver todas as demandas que a situação de doença requer, visto que esse processo contribui para a instalação de uma crise no núcleo familiar.

Tendo em vista esses aspectos, o objetivo proposto consiste em fazer um levantamento das dificuldades vivenciadas pelos familiares cuidadores de pacientes oncológicos e verificar as técnicas de suporte apontadas pela literatura para eles.

Assim, será apresentada uma pequena fundamentação teórica acerca do assunto e a seguir encontram-se os dados obtidos por meio

* Acadêmica do 5ำ ano de Psicologia do Cesumar Centro Universitário de Maringá (PR).

** Docente do curso de graduação em Psicologia do Cesumar - Centro Universitário de Maringá (PR), Doutoranda em Psicologia Clínica- PUCSP, Mestre em Educação - UEL. 
Volpato, F. S. \& Santos, G. R. S. Pacientes oncológicos

de uma pesquisa de cunho qualitativo e quantitativo realizada com 16 familiares cuidadores de pacientes oncológicos. Dentre os diversos aspectos levantados na entrevista estruturada podemos destacar: a mudança das atividades da rotina diária, o sentimento desses familiares com relação aos cuidados prestados e a comunicação entre familiar cuidador e paciente.

\section{Desenvolvimento}

\subsection{Fundamentação teórica}

O câncer é uma patologia que há séculos vem se propagando na sociedade. Apesar dos avanços científicos, se desconhece o número de novos casos diagnosticados a cada ano devido à ausência de um sistema de saúde de registro de câncer, que cubra todo o território nacional. Segundo o INCA - Instituto Nacional de Câncer (2006), as estimativas anuais de incidências são consideradas de grande valia, e as estimativas apresentadas para o ano de 2006 apontam que no Brasil poderão ocorrer 472.050 novos casos de câncer. Os tipos mais incidentes, exceto os de pele não melanoma, serão os de próstata e pulmão no sexo masculino e mama e colo do útero para o sexo feminino. Essa mesma magnitude é observada no mundo todo.

Dentre os diversos fatores que têm contribuído para isso podemos destacar o envelhecimento populacional, resultante do intenso processo de urbanização e das ações de promoção e recuperação da saúde, que proporcionaram a exposição contínua a fatores ambientais e mudanças comportamentais responsáveis pela carcinogênese.

Como em muitos casos, o paciente com diagnóstico de câncer precisa de uma ajuda contínua em sua vida diária. Surge a necessidade de um familiar se dedicar a esses cuidados, que são essenciais não apenas no momento de doença, mas ao longo da vida do ser humano. Assim o cuidado é parte integrante da vida. 
Carvalho (2003, p. 34) diz que o cuidar é um "elemento essencial dos fenômenos envolvidos nas relações que se estabelecem entre viver e morrer", é um cuidar que se reveste de múltiplos aspectos.

A definição apresentada por Boff (1999) para o cuidar é:

Cuidar é mais que um ato; é uma atitude. Portanto, abrange mais que um momento de atenção, de zelo e de desvelo. Representa uma atitude de ocupação, preocupação, de responsabilidade e de envolvimento afetivo com o outro (BOFF, 1999, p. 33).

A partir de então, pode-se pensar e falar no cuidado como algo vivido por nós e que em nós se estrutura, ou seja, nós seres humanos somos cuidados e sem o cuidado deixamos de ser humanos. Sendo assim, Boff (1999) apresenta a origem da palavra cuidado a partir do latim curar que eram utilizadas como sinônimos, num contexto de relações de amor e amizade expressando o desvelo, preocupação e inquietação pela pessoa amada. $O$ cuidado surge somente quando a outra pessoa tem importância para o cuidador, para assim, dedicar-se à pessoa cuidada, dispondo-se a participar do seu destino, buscas, sofrimentos, sucessos, enfim, da sua vida, sendo que o cuidado transforma-se em bom trato para com outro. Em função desse voltar-se ao outro, a atitude de cuidar também gera preocupações, inquietações e responsabilidades por parte de quem cuida.

Além dos aspectos já citados, Waldow apud Carvalho (2003) destaca que o cuidado incita dentro de nós seres humanos compaixão, solidariedade e ajuda, buscando a promoção do bemestar dos pacientes, assim como sua integridade moral e dignidade enquanto pessoas. Dessa maneira, os cuidadores devem manter a intencionalidade integrada ao ato de cuidar.

A denominação cuidar está na maioria das vezes associada à relação de dependência do paciente ou pessoas que precisam de cuidado. Por esse motivo, o cuidado faz parte de um processo de interação interpessoal. Paulo Freire apud Carletti \& Rejani (1996) afirma que, para que não ocorra uma dominação e manipulação por parte dos cuidadores sobre os pacientes é necessária uma co- 


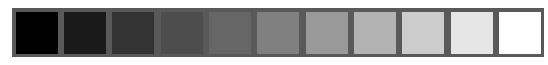

Volpato, F. S. \& Santos, G. R. S. Pacientes oncológicos

participação ativa das experiências anteriores e um esforço comum entre ambos para conhecerem a realidade e junto buscarem o crescimento sem distorções.

Cuidar ainda pode significar, numa visão integral, para Fernandes (2005), um escutar acolhedor das diversas dimensões do humano, numa postura de respeito ao homem e à sua natureza, integrando a prática dos saberes da saúde e do bem-estar. Deve-se observar nesse cuidar a busca pela unidade da pessoa como um todo, estimulando a crer na sua própria força, incentivando sua coparticipação no tratamento, pois com suas forças e fraquezas, vontade de viver e da busca pelo novo sentido da vida o paciente transforma-se no sujeito ativo e não no protagonista da sua doença.

Como a própria palavra sugere, cuida-dor é também aquele que cuida da dor, conforme enfatiza Franca (2004), que além de cuidar do paciente acometido por uma doença, torna-se alvo de todos aqueles que o cercam, inclusive a própria família. Fica também a encargo do cuidador suportar as exigências que the são impostas pelo meio familiar, pela doença e por si mesmo.

Por cuidadores, podemos definir todas as pessoas envolvidas no atendimento das necessidades dos pacientes, sejam elas físicas e/ou psicossociais. Dessa forma, Carvalho (2004) enfatiza: os cuidadores podem ser tanto a equipe de saúde como os familiares do próprio paciente; neste caso, iremos nos ater aos familiares cuidadores em função dos objetivos propostos.

Muitas vezes, este não escolhe ser cuidador, ele é "eleito" de maneira inconsciente pelo grupo familiar e se deixa colocar nesse lugar. Franca (2004) esclarece algumas circunstâncias que podem contribuir para isso, tais como: habitação, fatores econômicos etc. Há ainda outras questões, que quando trabalhadas terapeuticamente hão de surgir, como a aceitação para permanecer como "bodeexpiatório" ou como "aparador" do sofrimento do grupo familiar.

Para McCoughlan (2004), o maior presente recebido pelos cuidadores é a habilidade de estar presente com o paciente que se encontra em desconforto e auxiliá-lo com a intenção de lhe proporcionar o maior 
conforto possível. Através dessa prática, os cuidadores são beneficiados com o aprendizado e o recebimento de algo muito maior do que se oferece, assim como o respeito pela condição humana, a fragilidade do próprio ego, planos e sonhos e, entre outros, a partilha das experiências passadas. Um dos maiores privilégios dos cuidadores é ajudar o paciente a sentir-se melhor somente com as mãos, o coração e a mente.

$O$ ato de cuidar também é influenciado pelas características individuais de cada ser humano, assim como ressaltam Bettinelli, Waskievicz \& Erdmann (2004). Entretanto, cada cuidador é um ser diferente, com potencialidades, capacidades, que vive momentos diferentes atribuindo significações distintas aos seres humanos, por isso, ao tomar consciência desses elementos, os cuidadores terão capacidade para corresponder às demandas de sua vida diária. Da mesma maneira e com certa liberdade para fazer suas escolhas, o cuidador conseguirá redirecionar e transformar a realidade do seu cotidiano, só que para isso terá de abdicar dos interesses individuais percebendo melhor o coletivo, fator decisivo do processo saúde-doença.

Portanto, Bettinelli, Waskievicz \& Erdmann (2004) afirmam que é extremamente importante tomar conhecimento das suas potencialidades e limitações enquanto cuidadores, pois esses limites precisam ser superados para quebrar a barreira da onipotência e da mesma maneira possibilitar a construção da própria identidade por meio de cada atitude de cuidado para com a vida, até chegar a um momento de completude no desempenho do cuidado.

Há diversos estudos que giram em torno da assistência aos familiares, pacientes e cuidadores de acordo com McCoughlan (2004), principalmente no que diz respeito à capacidade de aprendizagem que esses indivíduos possuem para lidar com os aspectos existenciais, espirituais, psicológicos e emocionais do viver e morrer, assim como perda, luto, ansiedade, depressão e estresse; todos esses sentimentos e processos com os quais os familiares cuidadores estão envolvidos constantemente nas suas atividades. 


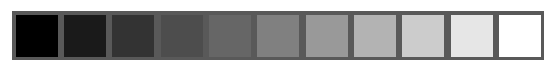

Volpato, F. S. \& Santos, G. R. S. Pacientes oncológicos

O cuidador assume um compromisso com o paciente por meio do cuidar, conforme afirma Mayeroff citado por Carvalho (2003), em que o cuidador precisa "entrar" no mundo do paciente como se fosse seu para assim ser capaz de entendê-lo, compreendê-lo, ver a vida como o paciente a vê e proporcionar-Ihe o que ele precisa para crescer.

Para usufruir as características positivas da função de cuidador, McCoughlan (2004) ressalta que tanto a família quanto os cuidadores precisam aprender uma habilidade essencial, que é cuidar de si próprios, tanto física quanto emocionalmente, pois essa é uma atividade que exige 24 horas de vigilância e cuidado ao paciente.

Todos os aspectos comentados até o momento são extremamente importantes para que o ato de cuidar seja assumido pelo familiar cuidador de maneira equilibrada e harmoniosa envolvendo-se com a mesma atenção e responsabilidade em todas as situações. Silva apud Carvalho (2003) esclarece que quando o cuidado é expresso por meio de uma atitude de qualidade, intensa e honesta, proporcionando uma verdadeira ajuda ao paciente, o tempo que se dedica deixa de ser o mais importante.

Inúmeras vezes o cuidador sente-se agredido ao ter de exercer a sua atividade de cuidar sem sentir-se amparado, conforme enfatiza Do Valle (2002). Além disso, está em constante contato com o outro que sofre, podendo desencadear o sofrimento do cuidador ou a possibilidade de vir a sofrer. Essa dor que se sobrepõe a todas as outras é denominada de dor psíquica, é a dor de existir, a dor de amar, pois o objeto ao qual o cuidador está ligado (o paciente que cuida com zelo, dedicação e atenção) é igualmente amado, odiado e angustiante.

O homem sente-se ameaçado pelo seu sofrimento, que pode surgir de três direções, segundo Freud (1930): (a) do nosso próprio corpo, condenado à decadência e à dissolução, não podendo dispensar nem ao menos o sofrimento e a ansiedade como sinais de advertência; (b) do mundo externo, que pode voltar-se contra nós por intermédio das forças de destruição; e (c) de nossos relacionamentos com as outras pessoas. Talvez este seja o mais penoso de todos, ao qual o cuidador está exposto com maior intensidade devido à sua relação direta com o paciente. 
Sobretudo, Freud (1930) afirma que o homem busca maneiras para lidar com o sofrimento advindo dos relacionamentos humanos com três atitudes: (a) da intoxicação; (b) podendo tornar-se membro da comunidade e utilizar-se de uma técnica científica para atacar a natureza sujeitando-a à vontade humana; $\mathrm{e}$ (c) a defesa imediata do isolamento voluntário, em que o familiar cuidador irá manter-se distanciado do paciente, realizando somente os cuidados necessários, podendo obter a felicidade da quietude.

Diante do sofrimento do cuidador pode acontecer uma baixa na resistência orgânica e ele ficar exposto a doenças físicas e até mesmo à depressão, conforme ressalta Franca (2004). Seu estado psicológico e emocional também é afetado sendo comum a expressão de afetos contraditórios que muitas vezes se intercruzam, tais como a raiva, a mágoa e a culpa. A culpa é o grande pesar, sentem-se culpados por terem esses sentimentos que culturalmente não se pode manifestar e sentir, principalmente por aqueles que sofrem.

Assim, os familiares cuidadores principalmente de pacientes que estão em fase terminal enfrentam um trabalho pesado, físico e mentalmente, que pode deixá-los emocionalmente esgotados, fisicamente exautos e completamente subjugados. Dessa forma, Lown \& Tavares citado por Silva, Maria (2004), comentam a importância dos familiares cuidadores de cuidarem de si mesmos para que possam se dedicar ao outro dignamente. Para isso é necessário descansar, comer bem, fazer exercícios regularmente, relaxar diariamente, meditar, rezar e quando preciso buscar aconselhamento.

Uma outra opção que Silva, Maria (2004) aponta é dar a oportunidade para o familiar cuidador falar sobre suas próprias ansiedades, seus medos, das questões que podem vir a acontecer nos próximos dias ou horas com a pessoa que ele ama e cuida, enfim, dar um suporte aos seus sentimentos.

Os cuidadores, da mesma forma que o paciente e a família, precisam ser ouvidos sobre seus anseios, angústias, medos, ansiedades e sentimentos. Rezende citado por Esslinger (2004) afirma que precisa haver uma interação nessa escuta, mas sem a 


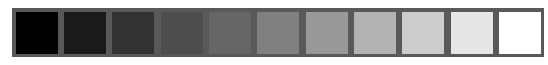

Volpato, F. S. \& Santos, G. R. S. Pacientes oncológicos

preocupação de obter conclusões, pois assim, ela se torna mais importante do que qualquer técnica.

Esslinger (2004) ainda ressalta que essa escuta deve ser atenta não apenas para o verbal, mas deve-se observar o que muitas vezes não é dito, como um olhar, um suspiro, choro, ou seja, perceber os sinais expressos pelos sentidos para que dessa maneira os familiares cuidadores sintam-se acolhidos, pois eles formam o elo entre paciente e a equipe de saúde, o que ocasiona um grande desgaste. Além de ser ouvido precisa também receber instruções e orientações detalhadas acerca do paciente, do tratamento, do diagnóstico, de todos os aspectos envolvidos nessa relação, numa linguagem simples e acessível ao cuidador.

Portanto, é essencial que os familiares cuidadores renovem o ar dos seus pulmões e não fiquem constantemente presos aos cuidados com o paciente. Kübler-Ross (1998) comenta que todos os seres humanos precisam ter suas "baterias recarregadas" e de vez em quando viverem uma vida normal para ser eficiente perante a doença, o paciente e os cuidados prestados.

Ao falarmos de familiares cuidadores, mencionamos uma complexidade grandiosa diferentemente de qualquer outro sistema, conforme apontam Carter \& McGoldrick (1995). Uma família quando recebe o diagnóstico de câncer em um dos seus membro sofre certas mudanças que variam de acordo com a atitude do paciente, do conhecimento e da habilidade de comunicação por parte de quem comunicou o fato. Kübler-Ross (1998) enfatiza a necessidade dessa família de compartilhar suas preocupações comuns para aliviar as pressões e emoções, que, se forem mantidas em segredo, podem criar uma barreira artificial que dificultará a preparação para o futuro.

Para a maioria das pessoas, a família representa um apoio muito importante tanto na estruturação dos vínculos afetivos como nos referenciais de segurança. O paciente portador de doença crônica geralmente vivencia uma série de experiências emocionais. Conforme afirmam Santos \& Sebastiani (2001), são manifestações psicológicas que o remetem a condições primitivas e a uma necessidade de sentir-se amparado e protegido, principalmente 
pelas figuras que já ocuparam esse papel e que nesse momento são solicitadas novamente.

Entretanto, Santos \& Sebastiani (2001) ressaltam que a família passa a ter um papel decisivo frente a essa nova fase de adaptação do paciente, prestando-Ihe auxílio, contribuindo com o trabalho de equipe de saúde e, em alguns casos, chegando até mesmo a comprometê-lo. Mas nem sempre se pode esperar que essa família tenha uma estrutura perfeita para absorver todas as demandas que as situações de doença e internação impuseram aos seus componentes, pois com esse processo de doença há também a instalação de uma crise no núcleo familiar.

Para que haja uma melhor compreensão acerca dos processos da psicodinâmica familiar, Santos \& Sebastiani (2001) enfatizam a necessidade de se perceber a família como um sistema de relações fechado e interdependente, ou seja, a família quando composta de todos os seus membros encontra-se num certo equilíbrio; sobretudo quando um dos componentes adoece, há uma privação familiar desse indivíduo em função das limitações da doença, o que gera um desequilíbrio (que pode ser temporário ou definitivo), perdendo um dos seus pontos de referência e sustentação. Essa crise que agora se instala passa a mobilizar tanto no sistema familiar como no paciente novas formas adaptativas de reorganização frente à crise, numa tentativa de criar uma situação temporária de equilíbrio para, assim, superá-la e resgatar o status quo.

Em função dessa desorganização e tentativa de reencontrar o equilíbrio, mesmo que seja temporário, a identidade e integridade do sistema são ameaçadas. Essa sensação, que segundo Santos \& Sebastiani (2001) pode ser objetiva ou subjetiva, mobiliza os integrantes da família podendo desencadear os mais diversos comportamentos em relação à pessoa que adoeceu, à equipe de saúde, ao tratamento e até mesmo aos próprios membros da família.

Há três níveis de reações que podem ser observados com maior freqüência frente a esses momentos de crise, conforme Santos \& Sebastiani (2001) ressaltam. São eles: (a) o mais comum, que é 


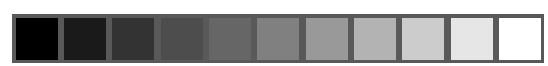

Volpato, F. S. \& Santos, G. R. S. Pacientes oncológicos

quando o sistema se mobiliza na intenção de resgatar seu estado anterior; (b) o sistema paralisa frente à situação de crise impactante; e, (c) o sistema familiar percebe os benefícios ocasionados pela crise e se mobiliza para mantê-la.

Como podemos perceber, a família tem importância fundamental no processo de relação do paciente com a doença, com o tratamento e até mesmo com a hospitalização. Portanto, podemos considerála um aliado no acompanhamento do paciente crônico, pois é ela quem irá conviver com o paciente e sua doença compartilhando juntos suas perdas e limitações, buscando apoio e conforto nas horas difíceis.

\subsection{Método}

Quanto à metodologia, utilizou-se uma análise de tratamento qualitativa dos dados obtidos, pois por meio do método interpretativo há a possibilidade de um estudo das questões abertas e uma leitura dos aspectos psicológicos e afetivos apresentados pelos cuidadores. De acordo com Pope \& Mays (2005), esse método procura explorar as compreensões subjetivas das pessoas acerca da sua vida diária.

O método quantitativo também foi utilizado com o objetivo de proporcionar um levantamento numérico e estatístico das questões fechadas, além de trazer um cruzamento de dados por essas questões.

Considerando que muitos familiares cuidadores verbalizaram não ter condições de prestarem as informações solicitadas respondendo ao questionário, justificando-se estarem vivenciando um sofrimento causado pela função que desempenham, o número de participantes restringiu-se àqueles que se dispuseram a respondê-lo no período da pesquisa. Dessa forma, justifica-se também a não mensuração do grau de instrução dos participantes dessa pesquisa.

Para a escolha do método procurou-se observar os procedimentos adotados, visto que Nascimento (2002) caracteriza a pesquisa quantitativa em função do seu caráter de descobrir e classificar a 
relação entre variáveis, a investigação da relação de causalidade e fenômenos, e a quantificação de opiniões e dados. Utiliza-se para isso os recursos e técnicas estatísticas.

Dessa forma, a amostra pode ser composta por sujeitos com características variadas que se distinguem segundo as necessidades do estudo. Moreira (2002) ressalta que para isso elabora-se uma lista de sujeitos e a escolha é realizada aleatoriamente.

Nesta pesquisa, a coleta de dados foi realizada com 16 participantes escolhidos aleatoriamente, que se encontravam na condição de familiares cuidadores de pacientes oncológicos havia no mínimo 4 meses. A condição de tempo visa atingir uma amostra que possibilita levantar o máximo de dados sobre as dificuldades por eles vivenciadas.

A técnica utilizada para a coleta de dados deste projeto foi uma entrevista estruturada, sendo que o instrumento compõe-se de 24 questões mistas.

O presente instrumento foi elaborado a partir de um levantamento realizado pela própria acadêmica, no qual, em tópicos, procurou-se listar as questões que seriam abordadas na entrevista, tais como sexo, idade, tempo que desempenha a função de cuidador, as tarefas diárias que foram alteradas na rotina do cuidador, como é a relação familiar cuidador/paciente, como está sua saúde física e mental, se apresenta sintoma depressivo, entre outros aspectos.

A partir de então as perguntas foram sendo estruturadas com as respostas, formando, assim, perguntas fechadas; algumas delas apresentam ao final a opção "outras", deixando a possibilidade de uma complementação da resposta caso o entrevistado não encontre a mais adequada anteriormente. Assim originaram-se as perguntas abertas.

Com todas as perguntas prontas, procurou-se montar a entrevista em uma ordem de perguntas que abordasse em primeiro lugar os dados do paciente, em seguida os dados do cuidador, para que depois se chegasse às questões referentes ao ato de cuidar e à saúde física e mental do familiar cuidador. 


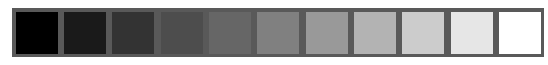

Volpato, F. S. \& Santos, G. R. S. Pacientes oncológicos

A princípio, o projeto o qual originou o presente trabalho foi encaminhado ao Comitê Permanente de Ética em Pesquisa do Cesumar - COPEC para aprovação da pesquisa com seres humanos. Após a liberação do certificado emitido pelo COPEC autorizando a realização da pesquisa, foi realizado um primeiro contato com a Secretaria Municipal de Saúde da cidade de Maringá (PR), em que se solicitou a liberação para desenvolver o projeto de pesquisa junto às Unidades Básicas de Saúde - UBS.

Após a liberação da Secretaria Municipal de Saúde de Maringá (PR) permitindo que a pesquisa fosse realizada junto as UBS, efetuouse então o primeiro contato com a diretoria dessas unidades, em que o projeto e seus objetivos foram apresentados, propondo, assim, uma parceria para que se tivesse acesso aos sujeitos dessa pesquisa.

A partir de então, com a indicação dos possíveis sujeitos, foi realizado um primeiro contato com os familiares para verificar se preenchiam os requisitos necessários para compor a amostra. Em caso afirmativo, explicou-se os objetivos do trabalho com a proposta da entrevista, verificando se o familiar cuidador poderia participar da pesquisa. Em todas as visitas realizadas, os familiares cuidadores aceitaram colaborar respondendo a entrevista. Quando possível foi aplicada já nesse primeiro encontro; caso contrário foram marcados outro dia e horário de acordo com a disponibilidade do participante. O Termo de Consentimento Livre e Esclarecido foi explicado a todos os participantes, que concordaram em assiná-lo.

Como o instrumento foi elaborado pela própria pesquisadora, por não haver nenhum outro que abrangesse os objetivos propostos, realizou-se uma pré-testagem para validar a entrevista. Assim, foi realizada uma primeira aplicação em um familiar cuidador que cumpria as determinações propostas. Como o participante respondeu todas as questões sem dificuldades, seguiu-se a coleta dos dados. 
Além dos dados oriundos da aplicação de uma entrevista sistematizada, pode-se mencionar também as informações coletadas por uma observação empírica, visto que os familiares cuidadores acabaram encontrando na pesquisadora alguém em quem poderiam depositar suas angústias, medos, fantasias etc. e, assim, relatar suas experiências e dificuldades nesse âmbito. Bem como verbalizou uma participante, "é importante poder conversar com alguém de fora para poder desabafar um pouco, porque é difícil se manter sempre forte. Tem horas que a gente desaba" (sic-P11).

Considerando ainda que a Psicologia é uma ciência que se volta para a subjetividade do ser humano, esses dados são extremamente importantes. As palavras da participante vêm reforçar o fato de que o familiar cuidador, além de se responsabilizar pelos cuidados ao paciente, também se torna alvo da própria família, precisando suportar as exigências que lhe são impostas por esse meio, pela doença e por si mesmo. Muitas vezes acabam não encontrando uma válvula de escape para suas emoções e sentimentos no ambiente familiar.

Os pacientes aos quais os familiares participantes dessa pesquisa dedicam seus cuidados podem ser caracterizados, em sua maioria, do sexo feminino $(56,3 \%)$, solteiros $(43,8 \%)$ e com idade entre 52 a 87 anos (50\%).

Já os familiares cuidadores são pessoas com a faixa etária entre 55 a 66 anos (37,5\%), do sexo feminino (81,3\%) e casados $(56,3 \%)$. Pode-se observar que a faixa etária dos pacientes $(50 \%$ entre 52 a 87 anos) e dos familiares cuidadores é condizente; portanto, ambos são pessoas que precisam de maiores cuidados em função das debilidades que o próprio envelhecimento proporciona.

Quanto ao grau de parentesco existente entre os familiares cuidadores e pacientes, os dados apontam para as relações conjugais (25\%), matriarcais e/ou patriarcais $(18,8 \%)$ e fraternais $(18,8 \%)$. Essas relações familiares permitem que o paciente possa vivenciar experiências emocionais e manifestações psicológicas primitivas expressando sua necessidade de sentir-se amparado e protegido. 


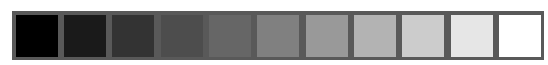

Volpato, F. S. \& Santos, G. R. S. Pacientes oncológicos

Dos 16 familiares cuidadores entrevistados, apenas cinco $(31,3 \%)$ afirmaram que o paciente não apresenta nenhum tipo de dependência. Em outros há uma dependência total $(37,5 \%)$ e parcial $(31,3 \%)$. Do total de 16 pacientes, três deles, que correspondem a 18,75\%, estão acamados. Dessa forma, observa-se uma relação entre a dependência existente e os cuidados necessários.

O grau de dependência que o paciente apresenta deve ser um fator irrelevante, pois o familiar cuidador deve prezar a unidade da pessoa como um todo e procurar estimulá-lo em sua própria força e participação no tratamento, bem como suas fraquezas, vontade de viver e a busca pelo novo sentido da vida transformando-o num sujeito ativo e não apenas num mero protagonista da sua doença.

Em geral, o diagnóstico de câncer causa um desequilíbrio no ambiente familiar, podendo ser temporário ou definitivo. Para compreender a dinâmica dessa crise se faz necessário atentar não apenas aos fatores biológicos da doença mas também ao mundo psicossocial numa tentativa de correlacioná-la ao ciclo de vida familiar.

Dos casos em estudo, 37,5\% da amostra receberam o diagnóstico no início da doença e os sintomas apareceram de forma acentuada com freqüentes crises agudas. Esses familiares sofreram mudanças afetivas e instrumentais num curto espaço de tempo, exigindo uma mobilização rápida no sentido de administrar esse desequilíbrio. Vivenciam ou vivenciaram uma grande tensão, pois a energia familiar é dividida entre proteger-se de outros danos, da desintegração e até mesmo da morte e também dos esforços progressivos para se reestruturar ou resolver o "problema".

Os pacientes que apresentam os sintomas há algum tempo e adiam a procura por um médico, $37,5 \%$ dos entrevistados, vivenciam juntamente com os familiares cuidadores um período sintomático que antecede o diagnóstico concreto. A fase de reajustamento e manejo, bem como do estabelecimento do plano inicial de tratamento, acaba sendo prolongada. Esse comportamento tanto dos familiares quanto dos pacientes revela um mecanismo de funcionamento em que, por meio da negação, tenta-se omitir a possibilidade do diagnóstico oncológico. 
Quando ocorre um início gradual, no qual os sintomas vão aparecendo aos poucos e logo os médicos chegam a um diagnóstico, 18,8\% dos casos, a família dispõe de um período de ajustamento prolongado, proporcionando-lhe um enfrentamento da doença de modo estruturado.

Apenas um dos familiares cuidadores entrevistados relatou ter diagnosticado o câncer na fase terminal da doença (6,3\%): "os médicos disseram que não tem condições de fazer cirurgia nem quimioterapia, por isso todos os cuidados estão sendo oferecidos em casa mesmo. Disseram que ela tem de três a seis meses de vida". Para esta família os aspectos referentes à morte são inevitáveis e os sentimentos que os circundam estão associados ao luto e à resolução da perda.

A seguir pode-se verificar alguns comentários acerca da descoberta do diagnóstico de câncer do paciente:

"Já faziam três anos meio que os médicos disseram do câncer, mas agora eles disseram que já não tem mais jeito, que está tudo tomado. Mas ela continua fazendo o acompanhamento e o tratamento." (P1)

"O Z. estava viajando (paciente é caminhoneiro) e começou a se sentir mal, mas como sempre ele não falou nada pra ninguém, até que um dia, né, eu estava na beira da pia fazendo almoço e ele apareceu do nada. Eu até levei um susto, porque ainda não era hora e nem dia de ele chegar. Mas aí, ele estava muito mal, não conseguia nem falar, a voz nem saía, aí corremos com ele pro médico e já tiveram que fazer a traqueostomia pra ele poder respirar. Ele quase morreu". (P8)

"Ele foi num médico que falou que era sinusite, foi em outro, fez os exames e falou a mesma coisa, só que pediu pra consultar um especialista. Daí, ele demorou mais de um ano pra ir neste outro médico". (P10)

"Logo que ele nasceu eu comecei a perceber que ele tinha um brilho diferente nos olhos, parecia uma manchinha, mas quase ninguém conseguia ver, então eu levei ele no pediatra que teve bastante dificuldade pra conseguir ver e acabou encaminhando pra outro 


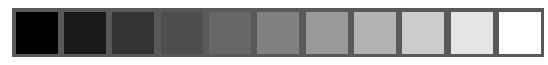

Volpato, F. S. \& Santos, G. R. S. Pacientes oncológicos

médico e logo me mandou pra SP, que é o único lugar que cuida desse tipo de câncer". (P12)

Os familiares cuidadores entrevistados vivenciam experiências diversas relacionadas à descoberta do câncer, o que interfere na estruturação e organização familiar, dificuldades, sentimentos e tarefas característicos de cada fase. Pode-se afirmar, também, que uma grande maioria dos familiares cuidadores $(75 \%)$ compartilham a mesma expectativa acerca de uma possível perda (morte) do paciente, pois diante do diagnóstico de câncer e com o avanço da doença torna-se inevitável o contato com esses conteúdos. Segue os dizeres da participante P3: "a gente sabe que ele não vai muito longe, os médicos disseram que não tem como fazer cirurgia e nem ao menos a radioterapia não vai resolver, ele está muito fraco" (sic).

Os entrevistados que responderam de forma negativa com relação à possível perda do paciente $(25 \%)$ podem estar utilizando o mecanismo de defesa de negação, pois o sofrimento que esse conteúdo gera é tão intenso e inadmissível que o indivíduo acaba negando essa realidade na tentativa de proteger-se.

Acerca dos questionamentos de como os familiares cuidadores consideram sua relação com o paciente, nove pessoas $(56,3 \%)$ relataram ter uma ótima relação, dos outros $43,8 \%$, seis pessoas $(37,5 \%)$ têm uma boa relação, mas com algumas dificuldades, e apenas um participante $(6,3 \%)$ apontou uma relação difícil. Podese exemplificar essas dificuldades de relacionamento pela fala dos familiares:

"Ele tem um temperamento muito forte, é uma criança muito determinada, de opinião, por isso às vezes temos dificuldades em lidar com ele". (P12)

"Ela é muito difícil de lidar, o problema maior é com o meu marido, porque ela se intromete em tudo e não pensa no que vai falar, e isso muitas vezes interfere na minha relação com ele". (P13)

Os dados obtidos sobre a relação pacientes e familiares cuidadores confirmam os números sobre a comunicação entre ambos, em que $50 \%$ da amostra conversam sobre todos os assuntos e $37,5 \%$ 
conversam sobre todos os assuntos, exceto os relacionados à doença. Nesses casos, percebeu-se que muitos dos pacientes desconheciam o diagnóstico de câncer. "Ele acredita que vai voltar a andar, aí eu procuro conversar com ele somente coisas boas, eu tenho medo de que ele fique sabendo que tem câncer e entre em depressão, aí ele pode morrer mais rápido" (P3). Essa falta de comunicação prejudica a ambos, pois em muitos casos esse "pacto de silêncio" se torna um estímulo à solidão e ao abandono; resulta em sofrimento.

Uma das formas que o familiar cuidador dispõe para melhorar essa comunicação e estimular o paciente a expressar seus sentimentos encontra-se no quanto ele está preparado para escutá-lo.

Pode-se verificar que nove $(56,3 \%)$ dos 16 familiares cuidadores desempenham essa função há menos de 1 ano, e o mesmo número de entrevistados se dedicam exclusivamente ao paciente em período integral. Apesar dessa atividade exigir 24 horas de vigilância e cuidado ao paciente, o tempo não se constitui no aspecto mais importante, visto que o cuidado muitas vezes pode ser expresso por uma atitude de qualidade, intensa e honesta, proporcionando ao paciente uma verdadeira ajuda.

Com tanta dedicação ao paciente os familiares cuidadores acabam precisando modificar sua vida pessoal em função do cuidar, como afirmaram $81,3 \%$ dos entrevistados. A única mudança que não ocorreu na vida desses cuidadores está relacionada ao estado civil.

Dos familiares cuidadores entrevistados, nove pessoas $(56,3 \%)$ responderam que precisaram abandonar todas as suas atividades em função dos cuidados, apesar da importância de manterem alguma atividade que considerem essencial para si próprios. Outros $43,9 \%$ conseguiram manter alguma atividade, seja ela uma atividade física, a prática religiosa seja o trabalho.

Relacionado às tarefas da rotina diária que os familiares cuidadores tiveram de alterar em função do ato de cuidar, apenas $12,5 \%$ dos entrevistados afirmaram que nenhuma atividade precisou ser alterada, outros $87,5 \%$ responderam haver diversas alterações. 


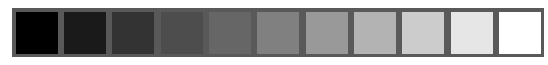

Volpato, F. S. \& Santos, G. R. S. Pacientes oncológicos

Desses, podemos destacar que $62,5 \%$ tiveram alterações no sono, $56,3 \%$ no lazer, $50 \%$ nos afazeres domésticos e $43,8 \%$ nas refeições.

Diante de tantas mudanças é de fundamental importância que o familiar cuidador possa cuidar de si próprio, procurando manter sua integridade emocional, psicológica e física para assim continuar dedicando-se ao paciente. Dentre as diversas formas de cuidados para consigo mesmo, o cuidador pode se dedicar por alguns minutos às técnicas de relaxamento, alongamento ou a alguma atividade que minimize sua tensão e lhe seja agradável.

Quanto à saúde física dos familiares, 50\% não perceberam oscilações após assumir a função de cuidador. Dos $50 \%$ que responderam positivamente, $25 \%$ começaram a apresentar insônia; $25 \%$ tristeza e depressão e $12,5 \%$ dores na coluna. Esses dados apontam que metade dos entrevistados apresenta algum tipo de sofrimento que está se expressando por meio do próprio organismo.

Portanto, pode-se perceber que os familiares cuidadores são pessoas propensas a adoecer com maior facilidade que os outros familiares ou amigos, pois, além de estar em contato direto com o paciente, o que pode lhe acarretar em sofrimento psíquico, bem como mobilizar seus conteúdos relacionados à morte, esses cuidadores apresentaram uma mudança abrupta em sua vida, sua rotina, suas atividades. Alguns deles inclusive relataram já perceber alguns sintomas psicossomáticos, por isso a importância de esses familiares reservarem um tempo para cuidar de si mesmos e assim poderem dedicar-se melhor aos cuidados com o paciente e desfrutar dos aspectos positivos dessa função.

Outro fator agravante para os familiares cuidadores é que $81,3 \%$ afirmaram não ter o auxílio de outras pessoas nos cuidados para com o paciente e apenas $18,8 \%$ podem contar com a ajuda de alguém. Desses, $81,3 \%$ têm a família auxiliando nos cuidados. Dessa forma, o familiar cuidador encontra maiores dificuldades em dedicar alguns minutos do seu dia aos próprios cuidados.

Quanto ao sentimento dos familiares enquanto cuidadores pode-se perceber que $43,8 \%$ da amostra dedicam seus cuidados ao paciente 


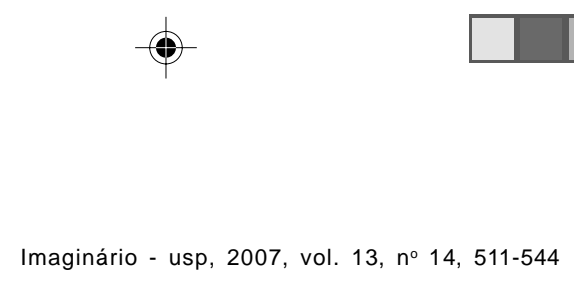

por sentirem um imenso amor ao próximo, já 37,5\% sentem-se úteis por poderem ajudar de alguma forma, apenas $12,5 \%$ sentem compaixão pela vida do próximo e $6,3 \%$ gostam de cuidar procurando não demonstrar tristeza ao paciente, pois não sabe se um dia irá precisar de cuidados também. Essas são as palavras de uma participante (P10) após mencionar que está casada com o paciente há 41 anos: "(...) é uma vida inteira juntos, por isso eu gosto muito de cuidar dele, ele sempre esteve comigo, é o companheiro da gente, né. E além disso, a gente nunca sabe se um dia vai precisar que o outro cuide de nós" (sic).

Mesmo que essa ação de cuidar esteja embasada no amor, há momentos conflituosos em que os familiares cuidadores sentem-se tristes, e então $87,5 \%$ dos entrevistados buscam auxílio em Deus, outros $12,5 \%$ procuram conversar com amigos ou familiares.

A necessidade de conversar com os amigos ou familiares sobre as suas tristezas consiste em compartilhar as preocupações para aliviar as pressões e emoções. Uma participante, P11, mencionou a importância de contar com os amigos da igreja, pessoas com quem pode conservar e até mesmo encontrar um apoio espiritual: "são meus amigos de oração" (sic).

Quanto à auto-estima dos familiares cuidadores, $75 \%$ não consideram que sua auto-estima foi afetada em função do ato de cuidar e apenas $25 \%$ responderam positivamente. Esse é um bom prognóstico dos familiares cuidadores, pois significa que a maneira como se sentem em relação a si mesmos permaneceu igual.

Dos familiares cuidadores entrevistados, $37,5 \%$ já retomaram algumas das atividades que tiveram de ser adiadas em função do ato de cuidar, mas $56,4 \%$ estão à espera de que algo aconteça com o paciente para poder retomar suas atividades. Desses, 31,3\% estão aguardando o paciente apresentar melhoras e adquirir um pouco mais de autonomia, $18,8 \%$ retomarão assim que o paciente falecer e $6,3 \%$ quando o paciente for para a casa de outro cuidador. Apenas $6,3 \%$ dos familiares já estão tentando retomar suas atividades. 


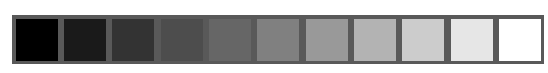

Volpato, F. S. \& Santos, G. R. S. Pacientes oncológicos

Esse é aspecto preocupante que os familiares cuidadores apresentam, pois, independentemente do paciente, precisam tentar retomar os seus planos de vida sejam eles individuais sejam familiares. Essa também é uma forma de cuidar de si próprios. Apenas o participante P6 conseguiu contratar uma auxiliar recentemente. Ela reside com os familiares e presta cuidados à paciente, assim o cuidador já está tentando retomar algumas atividades.

Por intermédio do relato ou do comportamento de alguns dos familiares pode-se observar algumas formas de funcionamento psíquico desses cuidadores. Percebeu-se que a participante P7 faz uso de determinados mecanismos de defesa, tais como a negação e racionalização, pois verbaliza estar "tentando continuar a vida normalmente". Pode ser uma das formas que ela tenha encontrado para lidar com o seu sofrimento diante dessa situação. E ainda mencionou que em uma das internações do paciente lhe ofereceram acompanhamento psicológico, mas recusou porque estava se sentindo bem. A cuidadora se utiliza desses mecanismos na tentativa de tentar se convencer de que a vida continua como antes do diagnóstico, mas mesmo assim chora quando vai tomar banho como uma forma de desabafo.

Por meio de todos esses dados podemos perceber que, apesar de muitos familiares cuidadores vivenciarem experiências parecidas, sentimentos em comum e até mesmo sofrerem pelos mesmos problemas, cada um deles reage diferentemente, tem uma atitude ou postura diferenciada, utiliza mecanismos distintos para lidar com todos esses elementos que estão emergindo em sua vida. Mas uma coisa ficou bastante evidente: todos apresentam diversas alterações em suas rotinas em função dos cuidados para com o paciente e expressam algumas dificuldades que aqui foram expostas.

\section{Considerações finais}

Uma família em que um de seus membros é acometido pelo câncer passa por diversas alterações e dificuldades, mas o familiar que se 
dispõe a ser o cuidador vivencia experiências únicas, relacionadas às mudanças necessárias e aos sentimentos desencadeados por essa ação.

Pode-se verificar que os familiares cuidadores apresentam algum tipo de sofrimento psíquico que se expressa por meio de tristeza, depressão, insônia, estresse, desânimo e até mesmo doenças psicossomáticas, como reações alérgicas e dores corporais.

As principais dificuldades desses familiares são lidar com a angústia que o paciente oncológico gera, bem como entrar em contato com os aspectos relacionados à morte. É nesses momentos conflituosos que os cuidadores buscam apoio em Deus, uma crença que transcende a natureza humana e conforta.

Outra dificuldade que os familiares cuidadores vivenciam está atrelada às mudanças que ocorrem na sua vida pessoal e rotina diária, visto que geralmente ele não tem o auxílio de outra pessoa nessa função de cuidar. Entre as diversas alterações, pode-se destacar as relacionadas a sono, alimentação, afazeres domésticos e lazer.

Como os familiares cuidadores dedicam-se a cuidar por sentirem amor, compaixão, preocupação e zelo para com o paciente, é importante que esteja bem consigo mesmo, visando proporcionar ao membro doente uma minimização do seu sofrimento e a busca do bem-estar.

Portanto, é fundamental que cuidem de si próprios, dediquem alguns minutos do dia a alguma atividade prazerosa, façam exercícios físicos, busquem utilizar técnicas de relaxamento e alongamento, procurem aceitar os seus próprios sentimentos e estabeleçam uma boa comunicação com o paciente. Assim, o familiar estará cuidando não apenas com as mãos, mas também com o coração e a alma.

Dessa forma, estará relacionando-se melhor com o paciente e poderá fazer dessa experiência vivida não apenas uma fonte de sofrimento, mas estará fazendo parte de uma escola em que o aprendizado é pelo respeito à condição humana. 


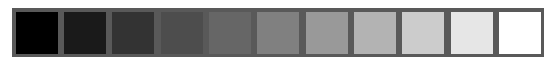

Volpato, F. S. \& Santos, G. R. S. Pacientes oncológicos

Como a presença da pesquisadora na residência do familiar cuidador serviu como um estímulo para que ele falasse sobre as suas dificuldades, pode-se verificar que muitos deles demonstraram uma necessidade muito grande de expressarem-se. Pude perceber em alguns casos um pouco da dinâmica psíquica daquele indivíduo, o que me proporcionou um enorme aprendizado sobre o ser humano, a escuta e muito mais sobre o amor para com o outro.

Portanto, seria de fundamental importância que esses familiares cuidadores pudessem ter um acompanhamento psicológico para auxiliá-los nessa tarefa de cuidar e também nos cuidados para consigo mesmos. É indicado para esses casos o aconselhamento psicológico, pois a proposta de trabalho volta-se para as tomadas de decisões que o indivíduo está vivenciando nesse momento. São necessários aproximadamente 10 encontros de 50 minutos, podendo variar de pessoa para pessoa. Os familiares cuidadores podem se beneficiar também de outros atendimentos, tais como a psicoterapia breve e a própria psicoterapia.

Pode-se destacar também a necessidade de o pesquisador estar preparado para ouvir esses familiares cuidadores, pois são conteúdos que muitas vezes acabam mobilizando alguns elementos internos, sejam eles conscientes sejam inconscientes.

Seria de fundamental importância a organização de grupos terapêuticos para familiares cuidadores de pacientes oncológicos, pois, por meio da experiência grupal, podem trocar informações, identificar e conhecer outras pessoas que estejam vivenciando problemas e sentimentos parecidos ou iguais, descobrir um espaço em que podem desabafar e também recarregar suas energias e, assim, dedicar-se melhor aos cuidados para com o paciente.

Resumo: Os pacientes oncológicos freqüentemente precisam de ajuda contínua em sua vida diária. Geralmente um dos familiares se encarrega dessas atividades, dedicando-se por um longo período a esses cuidados. O objetivo da pesquisa consiste em fazer um levantamento das dificuldades vivenciadas pelos familiares cuidadores de pacientes 
oncológicos e verificar as técnicas de suporte apontadas pela literatura para eles. A coleta de dados foi realizada por meio da aplicação de uma entrevista estruturada na residência de 16 familiares cuidadores de pacientes oncológicos, no mínimo há 4 meses, não importando sexo, idade e grau de instrução. A análise seguiu uma proposta qualitativa e quantitativa. Dos resultados obtidos pode-se afirmar que os familiares cuidadores de pacientes oncológicos são pessoas propensas a adoecer com maior facilidade, o que pode lhes acarretar em sofrimento psíquico, bem como mobilizar seus conteúdos relacionados à morte. Esses cuidadores apresentam uma mudança abrupta em sua vida, bem como em sua rotina. Alguns deles relatam já perceber alguns sintomas psicossomáticos. Conclui-se que é extremamente importante a esses familiares procurem reservar um tempo para cuidar de si podendo assim dedicar-se melhor aos cuidados para com o paciente e desfrutar dos aspectos positivos dessa função.

Palavras-chave: cuidadores, família/paciente, suporte psicológico.

\begin{abstract}
The patients with cancer quite often need a continuous help in their everyday life. Usually, one of the relatives is put in charge of these activities, dedicating him/ herself for a long period to such cares. The purpose of this research is to make a survey of the difficulties experienced by the caretaking relatives of oncology patients and check the support techniques presented in literature to them. The data were collected through interviews with 16 relatives that take care of patients with cancer for at least 4 months, without considering sex, age or instruction level. The analysis followed a qualitative and quantitative proposal. From the results found, we can be sure that the relatives that take care of patients with cancer are people prone to get sick easily, what may cause a psychic suffering to them and thoughts about death. These
\end{abstract}




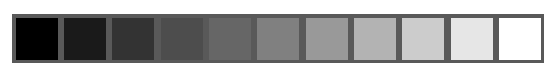

Volpato, F. S. \& Santos, G. R. S. Pacientes oncológicos

caretakers present a sudden change in their life as well as in their daily routine. Some of them reported that they have already identified some psychosomatic symptoms. We concluded that it is extremely important that these relatives try to take some time to take care of themselves. Doing that, they will be able to dedicate themselves to their relatives with cancer in a more effective way and enjoy the positive aspects of their duty.

Key words: caretakers, family/patient, psychological support.

Resumen: Los pacientes oncológicos frecuentemente necesitan ayuda continua en su vida diaria. Generalmente uno de sus familiares se encarga de esas actividades, dedicándose por un largo periodo a esos cuidados. El objetivo de la pesquisa consiste en hacer un levantamiento de las dificultades vivenciadas por los familiares cuidadores de pacientes oncológicos y verificar las técnicas de soporte apuntadas por la literatura. La recolección de datos fue realizada por medio de la aplicación de una entrevista estructurada en la residencia de 16 familiares cuidadores de pacientes oncológicos, hace por lo menos 4 meses, no importando sexo, edad y nivel de instrucción. El análisis siguió una propuesta cualitativa y cuantitativa. De los resultados obtenidos se puede afirmar que los familiares cuidadores de pacientes oncológicos son personas propensas a enfermarse con más facilidad, lo que puede provocarles sufrimiento psíquico, así como movilizar contenidos relacionados a la muerte. Esos cuidadores presentan un cambio abrupto en su vida, así como también en su rutina. Algunos de ellos relatan percibir algunos síntomas psicosomáticos. Se concluye que es extremamente importante que esos familiares busquen reservar un tiempo para cuidar de si, permitiendo dedicarse mejor a los cuidados para con el paciente y disfrutar de los aspectos positivos de esa función. 
Palabras clave: cuidadores; familia/paciente; soporte psicológico.

BETTINELLI, L. A.; WASKIEVICZ, J.; ERDMANN, A. Humanização do cuidado no ambiente hospitalar. In: PESSINI, L.; BERTACHINI, L. Humanização e cuidados paliativos. 2. ed. São Paulo: Loyola, 2004. cap. 5 , p. 87-100.

BOFF, L. Saber cuidar: ética do humano - compaixão pela terra. 10. ed. Rio de Janeiro: Vozes, 1999. 199 p.

BRASIL. Ministério da Saúde. Secretaria de Atenção à Saúde. Instituto Nacional de Câncer. INCA. Disponível em: <http://www.inca.gov.br> Acesso em: 21 abril 2005.

BRASIL. Ministério da Saúde. Secretaria de Atenção à Saúde. Instituto Nacional de Câncer. Coordenação de Prevenção e Vigilância. Estimativa 2006: incidência de câncer no Brasil. Rio de Janeiro: INCA, 2006. Disponível em: <http://www.inca.gov.br/estimativa/ 2005/> Acesso em: 01 setembro 2006.

CARLETTI, S. M. de M.; REJANI, M. I. Atenção domiciliária ao paciente idoso. In: PAPALÉO NETTO, M. Gerontologia: a velhice e o envelhecimento em visão globalizada. São Paulo: Atheneu, 1996, cap. 37 , p. 415-430.

CARTER, B.; MCGOLDRICK, M. As mudanças no ciclo de vida familiar: uma estrutura para a terapia familiar. In: CARTER, B.; MCGOLDRICK, M. e cols. As mudanças no ciclo de vida familiar: uma estrutura para a terapia familiar. 2. ed. Porto Alegre: Artes Médicas, 1995. cap. 1, p. 7-29.

CARVALHO, M. V. B. de. O cuidar no processo de morrer na percepção das mulheres com câncer: uma atitude fenomenológica. 2003. 179 p. Tese (Doutorado em Enfermagem) - Escola de Enfermagem da Universidade de São Paulo, São Paulo. Disponível em: <http:// www.teses.usp.br/teses/disponiveis/7/7136/tde-15122003110011/publico/mara.tde.pdf>. Acesso em: 21 abril 2005. 


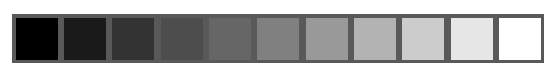

Volpato, F. S. \& Santos, G. R. S. Pacientes oncológicos

CARVALHO, V. A. de. Cuidados com o cuidador. In: PESSINI, L.; BERTACHINI, L. Humanização e cuidados paliativos. 2. ed. São Paulo: Loyola, 2004. cap. 20, p. 305-319.

DO VALLE, M. L. M. R. E quem cuida, não se cuida? Um olhar para o cuid(a)dor. Revista de cardiologia. Minas Gerais,v. III, n. 2, p.22-26, 2002.

ESSLINGER, I. De quem é a vida, afina?... Descortinando os cenários da morte no hospital. São Paulo: Casa do Psicólogo, 2004. 245 p.

FERNANDES, M. H. R. A importância da Psicooncologia. In: LOPES, V. L. B. Doutor, estou com câncer? Conduta médica e familiar nas comunicações dolorosas. 2. ed. Porto Alegre: Age, 2005. 175 p.

FRANCA, D. C. Cuidando do cuida-dor: atendimento psicológico no apoio do doente de Alzheimer. Revista Ciência e Profissão, v. 2004, n. 1, p. 50-52, abril 2004.

FREUD, S. O mal-estar na civilização. Edição Standad Brasileira das Obras Psicológicas Completas de Sigmund Freud, versão eletrônica, Rio de Janeiro: Imago, V. XXI, 1930.

KÜBLER-ROSS, E. Sobre a morte e o morrer. 8. ed. São Paulo: Martins Fontes, 1998, $296 \mathrm{p}$.

MCCOUGHLAN, M. A necessidade de cuidados paliativos. In: PESSINI, Leo; BERTACHINI, L. Humanização e cuidados paliativos. 2. ed. São Paulo: Loyola, 2004. cap. 11, p. 167-180.

MOREIRA, D. A. O método fenomenológico na pesquisa. São Paulo: Pioneira, 2002.

NASCIMENTO, D. M. da. Metodologia do trabalho científico: teoria e prática. Rio de Janeiro: Forense, 2002.

POPE, C.; MAYS, N. Pesquisa qualitativa na atenção à saúde. 2 ed. Porto Alegre: Artmed, 2005.

SANTOS, C. T. dos; SEBASTIANI, R. W. Acompanhamento psicológico à pessoa portadora de doenças crônica. In: ANGERAMI-CAMON, V. A. (org). E a Psicologia entrou no hospital... 3. ed. reimpr. São Paulo: Pioneira, 2001, cap. 3, p. 147-176.

SILVA, M. J. P. da. Comunicação com paciente fora de possibilidades terapêuticas: reflexões. In: PESSINI, L.; BERTACHINI, L. Humanização e cuidados paliativos. 2. ed. São Paulo: Loyola, 2004. cap. 16, p. 263-273. 


\author{
APÊNDICE \\ TERMO DE CONSENTIMENTO LIVRE E ESCLARECIDO \\ PARTICIPAÇÃO NA PESQUISA: PACIENTES ONCOLÓGICOS: UM \\ OLHAR SOBRE AS DIFICULDADES EXPERIENCIADAS PELOS \\ FAMILIARES CUIDADORES
}

\title{
Justificativa, objetivos e procedimentos
}

Ao receber o diagnóstico de câncer de um ente querido, toda a estrutura familiar sofre alterações, principalmente o membro que se dedicará aos cuidados desse paciente. São novas adaptações que esse cuidador terá de enfrentar, mas, diante dessa situação, como estão a sua saúde psíquica e suas relações sociais? Este estudo para o qual você está sendo convidado(a) a participar tem por objetivo fazer um levantamento das dificuldades vivenciadas pelos familiares cuidadores de pacientes oncológicos e verificar as técnicas de suporte apontadas pela literatura para eles. Será realizada uma entrevista composta por 24 perguntas, e os resultados poderão ser publicados em relatórios e artigos científicos.

\section{Liberdade de recusar ou retirar o consentimento sem penalização}

Você tem a liberdade de participar, recusar ou retirar o consentimento sem penalização.

\section{Garantia de sigilo e privacidade}

As informações de identificação serão mantidas em sigilo para preservar a privacidade do participante, ou seja, quando necessário serão utilizadas iniciais fictícias sendo suprimidas quaisquer informações que possam identificá-lo(a).

\section{Formas de ressarcimento e indenização}

Sua participação é voluntária, não havendo pagamento para os que participarem deste estudo. 
$\mathrm{Eu}$, após ter lido e entendido as informações e esclarecido todas as minhas dúvidas referentes a este estudo com a Professora Ms. Gilcinéia Rose dos Santos, CONCORDO VOLUNTARIAMENTE em participar dele.

Data:

Assinatura (do pesquisado ou responsável) ou impressão datiloscópica

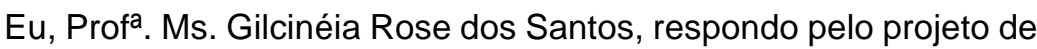
pesquisa em conjunto com a aluna Flávia Sordi da Silva. Declaro que prestei todas as informações e comprometo-me a conduzir todas as atividades deste estudo.

Para maiores esclarecimentos, entrar em contato com a pesquisadora no endereço abaixo relacionado:

Flávia Sordi Volpato

CESUMAR - Centro Universitário de Maringá

Av. Guedner, 1610, Jd. Aclimação

Maringá (PR)

Fone: (44) 3027-6360 
Entrevista realizada na data:

Horário:

Iniciais do cuidador:

Local da

entrevista:

\section{Dados do paciente}

1. Idade do paciente: anos

2. Sexo do paciente:
(a) Masculino
(b) Feminino

3. Estado civil do paciente:
(a) Solteira (o)
(b) Casada (o)
(c) Amasiada (o)
(d) Divorciada (o)
(e) Viúva (o)

4. Em que fase a doença foi diagnosticada?

(a) No início, de uma forma gradual. Os sintomas foram aparecendo aos poucos e logo os médicos chegaram ao diagnóstico.

(b) No início, sendo que os sintomas apareceram de forma bem acentuada, com freqüentes crises agudas.

(c) Já havia algum tempo que a (o) paciente vinha apresentando os sintomas, mas sua ida ao médico foi-se prolongando.

(d) Na fase terminal da doença 
Volpato, F. S. \& Santos, G. R. S. Pacientes oncológicos

5. Qual o grau de dependência do paciente em relação aos cuidados necessários?
(a) Total
(b) Parcial
(c) Não há dependência

\section{Dados do cuidador}

6. Idade do cuidador: anos

7. Sexo do cuidador:
(a) Masculino
(b) Feminino

8. Estado civil do cuidador:
(a) Solteira (o)
(b) Casada (o)
(c) Amasiada (o)
(d) Divorciada (o)
(e) Viúva (o)

9. Qual o grau de parentesco entre cuidador/paciente?
(a) Pai/mãe
(b) Marido/esposa
(c) Filho (a)
(d) Irmã (o)
(e) Avó/Avô
(f) Cunhado (a)
(g) Sogro (a)
(h) Outro:

10. Você considera a sua relação com o paciente:
(a) Ótima
(b) Boa, mas com algumas dificuldades
(c) Difícil
(d) Péssima 
11. Como é a sua comunicação com o paciente?
(a) Não há comunicação, pois o paciente não oferece abertura para tal.
(b) Não há comunicação, pois não tenho disposição para conversar com o paciente.
(c) Conversamos somente o necessário.
(d) Conversamos sobre todos os assuntos, exceto os relacionados à doença.
(e) Conversamos somente sobre a doença.
(f) Conversamos sobre todos os assuntos.

\section{Ato de cuidar}

12. Há quanto tempo desempenha a função de cuidador?
(a) Menos de 1 ano
(b) Mais de 1 ano
(c) Mais de 2 anos
(d) Mais de 3 anos

13. Quantas horas do dia você dedica exclusivamente ao paciente?
(a) Menos que 1 hora
(b) Mais que 1 hora
(c) Mais que 2 horas
(d) Mais que 3 horas
(e) Mais que 4 horas
(f) O tempo todo

14. Sua vida pessoal se modificou após assumir o papel de cuidador?
(a) $\operatorname{Sim}$
(b) Não

15. Seu estado civil permaneceu o mesmo enquanto desempenhava a função de cuidador? Se alterou para qual?
(a) $\mathrm{Sim}$
(b) Não: 
16. Quais as tarefas diárias da sua rotina que foram alteradas em função do ato de cuidar?
(a) Sono
(b) Refeições
(c) Parei de trabalhar
(d) Os afazeres domésticos
(e) O lazer
(f) Os estudos
(g) Outros:

17. Há alguma atividade que você manteve em sua rotina por ser essencial para a sua vida pessoal? Qual?
(a) Não
(b) Sim:

18. Você tem o auxílio de outras pessoas para ajudar a cuidar do paciente? Quem?
(a) Não
(b) Sim:

\section{Saúde física e mental}

19. Sua saúde física apresentou oscilações depois que começou a cuidar do paciente? Se a resposta for positiva; quais os sintomas apresentados?
(a) Não
(b)Sim:

20. Como se sente enquanto cuidador? (marcar apenas uma resposta)
(a) Sinto-me útil por poder ajudar de alguma forma
(b) Sinto um imenso amor ao próximo
(c) Compaixão pela vida do próximo
(d) Sinto vontade de desistir, abandonar
(e) Não gosto de prestar esse tipo de ajuda
(f) Outros: 
21. Em algum momento, você chegou a pensar numa possível perda (morte) do paciente?
(a) $\mathrm{Sim}$
(b) Não

22. Nos momentos de dificuldade pessoal (conflitos, tristeza), você busca auxílio de que forma? (marcar apenas uma resposta)
(a) Conversa com os amigos/familiares
(b) Procura ficar sozinho (a)
(c) Busco apoio em Deus (na igreja)
(d) Procuro um (a) psicólogo (a)
(e) Outro:

23. Você sente sua auto-estima afetada com o ato de cuidar?
(a) $\operatorname{Sim}$
(b) Não

24. Quando pretende retomar as atividades que teve de adiar em função dos cuidados prestados?
(a) Já retomei algumas
(b) Assim que a (o) paciente apresentar melhoras e adquirir um pouco mais de autonomia
(c) Vou arrumar uma (um) auxiliar para poder retomá-las
(d) Depois que a (o) paciente vier a falecer
(e) Outro: 


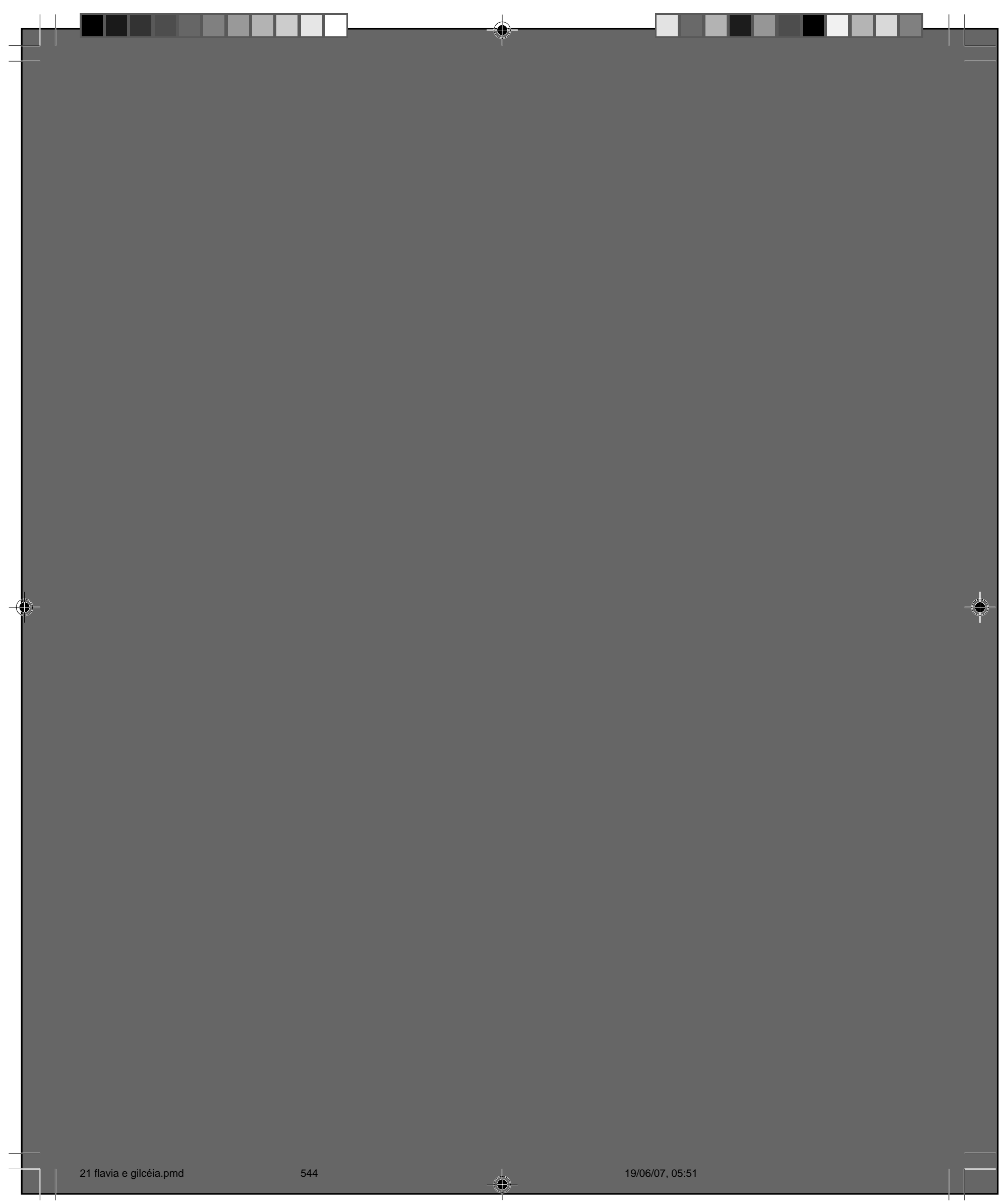

